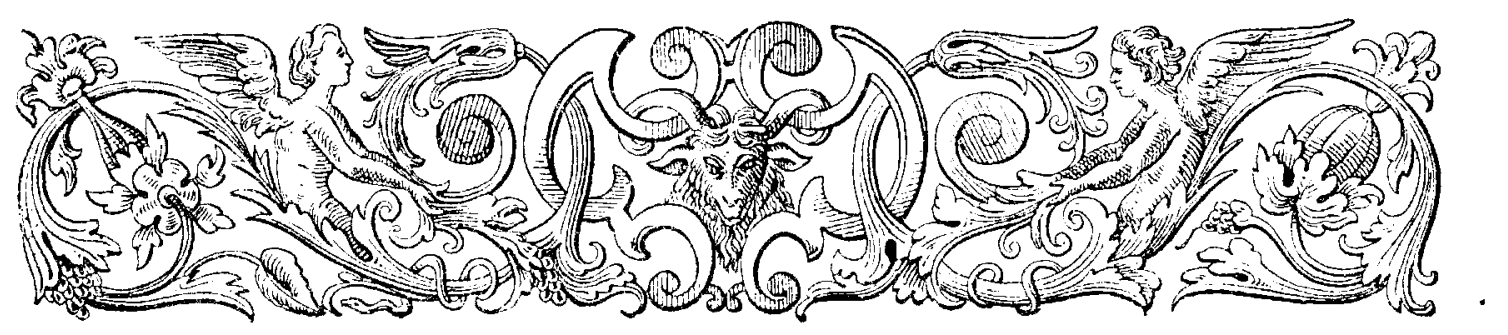

\title{
MEINDERT HOBBEMA
}

$\mathrm{DOOR}$

Mr. N. DE ROEVER.

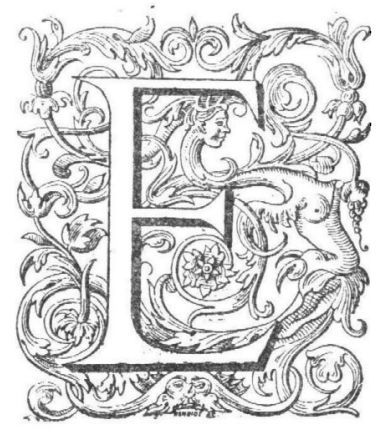

$\mathrm{K}$ is in het leven van niet weinige onzer groote kunstenaars veel wat voor het oog van den belangstellenden zoon der negentiende ceuw met een dichten sluier bedekt is. Wel hebben ijverige nasporingen van cen keurbende van geschiedvorschers het er toc gebracht, dat het dichte weefsel hier en daar een weinig ijler werd en een blik gunde op de gehcimenissen, die het verborgen hield, maar het volle licht drong daarmede nog nict binnen. Waar we de voorlichting van gelijktijdige biografen missen, zijn we enkele gegevens, soms zelfs het geraamte voor eene levensbeschrijving rijker geworden, maar wic daarmede cen beeld zou willen ontwerpen, zal spoedig bemerken, dat hij niets dan de eerste grondslagen ter zijner beschikking heeft, dat hij do matcrialen welke hij van clders niet kan aandragen uit het onderling verband van de bestaande moet aanvullen. Een ruim veld voor gissingen voorzeker. Verstandig hij, die zijne verbeelding geen te groot spel lait spelen, maar zich bepaalt tot het maken van zulke gevolgtrekkingen waartoe zijn gegevens hem wettigen.

Meindert Honhema (geb. te Amsterdam in den jare $16_{3} 8$ ) is een der meesters, die door de vroegere biografen nict wordt genocmd. Zijn reputatie drong niet door tot de achttiende eeuw, omdat hij zich geen naam had kunnen maken bij zijn leven. Het was, als of de wolk der vergetelheid zijne nagedachtenis zou blijven verduisteren. Maar de 
zon der vrijheid telde in haar stralenbundel een, die wars was van de conventioneele kunstschool der vorige eeuw, en, terwijl hij den wolk der vergetelheid scheurde, het oog, lang verzadigd aan hare mecstcrstukken, deed schouwen op de kunstwerken van de zeventiende ecuw, waaruit waarheid en realiteit sprak.

Toen herleefde Hoвbema, en hij deelde in de bewondering, die hot tegenwoordige geslacht in zoo ruime mate voor de heroën der kunst over heeft.

Maar Hobbema blcef cen nam van cen grooten kunstenaars-geest, die men huldigde, de persoon werd te vergeefs gezocht.

De eerste, die een zeker bericht van zijn leven vond, was JHR. W. I. C. RAmmelMAN ELZEVIER, archivaris van Leiden, de eerste die de aankondiging deed van zijn overlijden, voorgevallen in December I 709, was DR. P. SCHELTEMA, archivaris van Amsterdam. Door ELzEviER's vondst leerden we den meester kennen als de gelukkige bruidegom; SCIILLTEMA stelt hem ons voor als den meer dan 70-jarigen, verarmden, alleen van al de zijnen achtergebleven grijsaard, die kort na den dood van zijn trouwe gade het huis waar "het Schip de Hoop" in den gevel stond, verliet om zich in de nieuwe woning, zijne eenige dochter, de laatste hoop op de toekomst, die hem nog het hart verkwikken kon, door den dood te zien ontrooven.

En in dit tijdsverloop, besloten tusschen de jaren I 668 en I709, had hij vier malen vadervreugd gesmaakt, maar ook vier malen was hem dic vreugde oorzak geweest van de grootste smart, die een vader lijden kan. ')

Het is verwonderlijk, dat juist uit dit tijdsverloop geene andere schilderijen van den meester bekend zijn, dan het gezicht op Middel-Harnis met het jaartal r689. Eén werk in 40 levensjaren, en met een tusschenpoos van meer dan 20 jaren na het eerst daaropvolgende gedateerde stuk van I668, gaf grond tot het vermoeden van den een, dat het jaartal niet echt was, van den ander, dat de śchilder omstreeks 1670 moest overleden zijn.

Wat mocht de reden wezcn, dat HOBIEMA in 1668 , op pas 30 jarigen leeftijd het penscel nederlegde, om slechts nu en dan na lange jaren van rust het weder ter hand te nemen?

Zie daar een vraag die Schen'TEMA's bijdrage ons niet kon oplossen.

Het volgende geeft daarop het antwoord.

Een aanteekening in het boek der dagelijksche notulen van Burgemeesteren van den jare I709, wijst ons aan, in de eerste plaats welke de juiste dag van HoBbEMn's overlijden is, en in de tweede plaats, dat hij tot zijne dood eene eerzame, zij 't ook kleine post van vertrouwen binnen zijne geboortestad bekleedde. De aanteekening luidt:

„Op den io December I 709 hebben de wijnroeijers bekent gemaakt, dat haaren "Confrater Meynert Hobiema den 7 dezer overleden is."

Wat was den aard van de betrekking van wijnroeier, vraagt ge? Mijn antwoord

1) Zie de uittreksels uit de oude archieven van den Burgerlijken stand bij ScheLtema. Aemstels Oudheid (1863) deel V, blz. 63, 64. De aanvage voor HobbemA's begrafenis bewijst, dunkt mij, dat hij kinderloos overleed. 
moet u plotseling uit de $\mathrm{XVII}^{\mathrm{e}}$ eeuw terug voeren naar de XIV ${ }^{\mathrm{e}}$, toen Amsterdam van Hertog Albrecht het recht kreeg van de maat. $\mathrm{Nu}$ ben ik, hoor ik u zeggen, even wijs. Welnu, van oudsher was het cen voorrecht van den graaf om bij het ter marlit brengen of verkoopen van goederen, welke niet naar het gewicht of naar den maat van de verkoopplaats waren berekend, dic tc laten overwegen of overmeten volgens den daar geldenden maatstaf. Dat daaraan cenige onkosten verbonden waren, welke den grafelijken schatkist stijfden, of de beurs van den pachter, spreekt van zelf. De koopman getroostte zich die onkosten gaarne; kooper en verkooper konden nu geen verschil krijgen over de hoeveelheid der geleverde waar, hetgeen anders bij het bestaande verschil in gewicht en maat van alle steden maar al te wel mogelijk was.

In de vorige ecuw werd voor 't meten van een stuk brandewijn 12 stuivers, van een okshoofd wijn 3 stuivers betaald.

Dit grafelijk privilcge van mat verlireeg de stad in I389, „om ecn goede somme van blinkende penningren" en naar het schijnt wel te gelijk den maat van drooge en natte waren, wellse de graaf op anclere plaatsen niet altijd te gelijk verkocht heeft.

De stad deed gelijk de graaf en verpachtte oudtijds het ambt van weger of meter, maar van lieverlede beschouwden de overste regenten het als ecn hun toekomend voorrecht om met de betrekking ook de voordeelen weg te schenken aan personen, die zij om welke reden dan ook een klein ambtjo wenschten te bezorgen. Hobbema heeft alzoo in den gunst van een der Amsterdamsche burgemecsters moeten deelen.

De werkkring van den beëedigden wijnroeier was nict omslachtig, ofschoon hij bchalve den wijn, ook den brandewijn en de olie meten moest, wanneer zij in ongeijkte vaten werden aangevoerd of verhandeld. 't Schijnt dat de koopman slechts aan 't Wijn roeierskantoor, tegen de Nieuwe Kerk gelegen, een der ten tijde van Honbema 6, later ten tijde van WAGENAAR 5 ambtgenooten behocfle te ontbieden naar de pakhuizen waar hij zijn wijn, brandewijn of olie had opgeslagen, om zijn boodschapper, vergezeld van den wijnroeier met zijn werktuigen in de hand, te zien terugkeeren. De kleine voordeelen schijnen door de groote massa der gemeten goederen een niet onaanzienlijk cijfer te hebben beloopen. Ieder der wijnroeiers behield aanvankelijk de vruchten van zijn arbeid voor zich, maar juist in HOBBEMA's tijd is daarin eene verandering gekomen. Op verzoek der gezamenlijke wijnroeiers besloten burgeneesteren den $3 \mathrm{I}^{\text {ste }} \mathrm{Juli}$ I676 om hunne goedkeuring te hechten aan het door hen kenbaar gemaakte plan om voortaan alle winsten gezamenlijk te deelen, en uit den gemeenen kas de medebroeders, die „sieck, impotent oft andersints onbequaem" waren, wekelijks zes gulden uit te betalen. Dat is waarlijk voor dien tijd niet weinig! Nijpende armoede heeft HobBEMA dus nooit gekend, daarvoor was buitendien zijn ambt, zij het ook niet aanzicnlijk, te fatsoenlijk. Dat hij in de klasse der armen begraven werd bewijst alleen, dat hij geen geld en geen bemiddelde verwanten naliet; niet dat hij bij zijn leven armoede zou hebben geleden.

Wij vinden dit in eene acte geregistreerd in 't groot Memorial VI, bl. I82; daar- 
uit blijkt, dat zijn collega's toen waren : Rutger van SEyst, Johannes VAN DEN Driessche, Pieter van den Luffel, Gerrit K. Ryer en Cl. D. B. Commerroy. Hij teekende tusschen de beide eersten en schijnt dus naar den tijd van aanstelling de tweede te zijn geweest. Toch heeft hij hen allen overleefd.

Ik heb te vergeefs naar die aanstelling gezocht, maar eindelijk heb ik toch het jaar der aanstelling gevonden, en wel in de Ambtboeken en in de zoogenaamde, Heerenboekjes" waarin ook de namen en 't jaartal der aanstelling van de wijnroeiers staan opgegeven. Het Ambtboek blz. 169, zoowel als het Heerenboekje van I703 vcrmelden het jaar I 668 als dat van HoBBEMA's benoeming ${ }^{2}$ ). Dat deze opgave juist is, valt te bewijzen uit eene aanteekening in het derde der aanwezige registers der dagelijksche Notulen van burgemeesteren, blz. I, waaruit blijkt, dat er in Februari van dat jaar juist een plaats als wijnroeier door 't overlijden van PIETER LAURENsz van DEN HoEck was vacant geworden.

Opmerkelijk is het, dat zijne benoeming plaats had in 't zelfde jaar, waarin hij in 't huwelijk trad, hetgeen aanleiding geeft tot de veronderstelling, dat de voordcelen van 't wijnroeierschap zijn voornaamste bron van inkomsten waren en hem in staat moesten stellen de echtelijke woning interichten en het aanvankelijk kleine gezin tc onderhouden. Dat een kunstenaar als HobBema niet zonder eenige aandoening penseel en palet voor de peilwerktuigen, waarmede hij voortaan den klaren dag zou doorbrengen, ruilde, mogen we voor zeker houden. Ons is het thans verklaarbaar, dât we slechts één gejaarmerkt schilderij van den meester na 1668 kunnen aanwijzen.

Het schijnt evenwel, dat IOBBEMA zijn oude vrienden van het atelier of van den vrolijkcn taveerne, waar de schildersbent elkaar rendez-vous gaf, behield. Was het zijn leermeester JACOB VAN RUYSDAEL - men neemt althans aan, dat HoBBEMA zijn leerling was - die als getuige van den bruidegom optrad, een ander weinig bekend mar daarom evengoed geacht kunstenaar, JAN VAN KESSEL, die naar dcskundigen beweren, soms in den trant van RUvSDAEL geschilderd heeft, bleef in viriendschap met hem verbonden. Dic ontdekking is niet zonder belang, want er ligt een steun in voor het vermoeden van kunstkenners, dat JAN vaN Kessel en MEInder'T Hobbema beide leerlingen van RuysDAEL waren.

Ik ben echter nog het bewijs van het bestaan der vriendschapsband tusschen dic beide kunstenaars schuldig. Het ligt in het feit, dat MEInderT getuige was bij den doop van het kind van Johannes van Kesser en Clara Swigters, die in Februari 1675 in de Nieuwe Kerk te Amsterdam plaats had.

Wellicht kan ik later meer over dien weinig bekenden JAN VAN KESSEL mededeelen. Ik zeide zoo even, dat Hobuem in den gunst van een der Amsterdamsche burge-

1) Uit de Heerenboekjes blijkt huitendien - wat tot nadere plantsbepaling van HonBma's woning kan dienen - dat hij van 1703-1705 in cle Konijnenstraat bij de Lauricrgracht, van I706-1709 op de Rozengracht naast het Doolhof woonde. 
meesters gedeeld heeft. Raadplegen wij de regeeringslijst van den jare I668, dan zien we den naam van den Burgemeester LAMBERT REYNST bovenaan staan. Dit beteckent, dat hij gedurende 't eerste kwart-jaar - juist datgene, waarin, grclijk we zagen, de plaats aan 't wijnroeierskantoor openviel —, de voorzittersstoel innam. Deze magistraatspersoon was de vader van Corver.IS REYNsT ${ }^{1}$ ) dic als doopgetuige bij den doop van HobBEMA's zonen optrad. CORNELIS REXNST was, het blijkt hieruit, een goed vriend van het jonge gezin, en het is niet onmogelijk, dat Burgemeester REYNsT, door zijn voorspraak, HobBEMA met het geenszins te verwerpen ambt, dat hem een zorgeloos zij ook bescheiden bestaan verzekerde, heef begunstigd.

Of onze burgervader den kunstenaar daarmede wel zulk cen grooten dienst heeft bewezen, en of de voordeelen van het ambt hem even nuttig waren als ze voor cen ander zouden zijn geweest, mag voorwaar betwijfeld worden. Had HonBEMA van zijn penseel moeten leven, en was hij in de gelegenheid geweest zijn tijd en zijn krachten aan de kunst te wijden, dan zou hij wellicht meer nog met de zorgen en den strijd des levens te kampen hebben gehact, maar zijn talent had zich breed en in al zijn kracht ontwikkeld en hij zou niet onbekend, ongeacht bij zijn tijdgenooten als een schamel burger in de groeve zijn gedaald.

$\mathrm{Zijn}$ dood was geen gebeurtenis. Reeds lange jaren te voren was hij gestorven toen hij den loopbaan der kunst, mocielijk vaak, en de werkplaatsen van de gevierde kunstenaars in de achterbuurten vaarwel zei, en in den schaduw van 't achtste wereldwonder, verloren onder de menschenmassa, die in haastigen spoed het middenpunt der stad of het hart des koophandels van Holland trachtte te bereiken, het kleine wachthuisje van een nog kleiner college betrad, boven welks deur men had zorg gedragen te schilderen "Wijnroeijers-comptoir.,"

En toen den Ioden December I 709 van daar uit de boodschap naar de Heeren werd gebracht, dat een der collega's het tijdelijke met het eeuwige had verwisseld, toen zal de droefheid over het verlies van den medebroeler daar niet grooter zijn geweest dan de vreugde, die er heerschte, toen korten tijd later zijn opvolger AnTHONY EvNkMAN de ledige plaats innam.

Ilad slechts Hobbema een Six in plaats van een REysst gevonden!

1) CORNELis ReYNST kinderloos overleden en gehnwd met $\Lambda$ IFJEN DE HAEN, de dochter des vice-admiraals, was een zoon van den in $\mathbf{1} 672$ door den Prins uit de regeerings ambten ontslagen burgemeester LAMDERT RFrNST, geboren uit zijn huwelijk met ALIDA Brckek CoRnkis do. vgl.: Het Patriciaat van Amsterdam, vertegrenwoordigd door de genealogie van 't geslacht Boesess. (Amst. C. I. v. Langenhuyzen I88I), blz. 22. 